\title{
Ibuprofen before Exercise Does Not Prevent Cortical Bone Adaptations to Training
}

\author{
Vanessa D Sherk ${ }^{1}$, R Dana Carpenter ${ }^{2}$, Erin D Giles ${ }^{1}$, Janine A Higgins ${ }^{3}$, Robera M Oljira ${ }^{1}$, \\ Ginger C Johnson ${ }^{1}$, Samuel Mills ${ }^{2}$, and Paul S MacLean ${ }^{1}$ \\ ${ }^{1}$ Department of Medicine, University of Colorado Anschutz Medical Campus, Aurora, CO \\ ${ }^{2}$ Department of Mechanical Engineering, University of Colorado Denver, Denver, CO \\ ${ }^{3}$ Department of Pediatrics, University of Colorado Anschutz Medical Campus, Aurora, CO
}

\begin{abstract}
Using a nonsteroidal anti-inflammatory drug (NSAID) before a single bout of mechanical loading can reduce bone formation response. It is unknown whether this translates to an attenuation of bone strength and structural adaptations to exercise training.
\end{abstract}

PURPOSE-To determine whether NSAID use before exercise prevents increases in bone structure and strength in response to weight-bearing exercise.

METHODS-Adult female Wistar rats ( $\mathrm{n}=43$ ) were randomized to Ibuprofen (IBU) or Vehicle (VEH) and Exercise (EX) or Sedentary (SED) groups in a $2 \times 2$ (drug, activity) ANCOVA design with body weight as the covariate, and data are reported as mean \pm SE. IBU drops ( $30 \mathrm{mg} / \mathrm{kg} \mathrm{BW}$ ) or VEH (volume equivalent) were administered orally 1 hour before the bout of exercise. Treadmill running occurred 5 days/week for $60 \mathrm{~min} /$ day at $20 \mathrm{~m} / \mathrm{min}$ with a $5^{\circ}$ incline for 12 weeks. MicroCT, mechanical testing, and finite element modeling were used to quantify bone characteristics.

RESULTS—Drug*activity interactions were not significant. Exercise increased tibia cortical cross-sectional area (EX: $5.67 \pm 0.10$; SED: $5.37 \pm 0.10 \mathrm{~mm}^{2}$, p<0.01) and structural estimates of bone strength (Imax: EX: 5.16 \pm 0.18 ; SED: $4.70 \pm 0.18 \mathrm{~mm}^{4}$, p<0.01; $\operatorname{SecMod}_{\text {Polar }}$ : EX: 4.01 \pm 0.11 ; SED: $3.74 \pm 0.10 \mathrm{~mm}^{3}, \mathrm{p}<0.01$ ). EX had increased failure load (EX: 243 \pm 9 ; SED: $202 \pm 7 \mathrm{~N}$, $\mathrm{p}<0.05$ ) and decreased distortion in response to a $200 \mathrm{~N}$ load (Von Mises Stress at Tibia-Fibula Junction: EX: 48.2 \pm 1.3 ; SED: $51.7 \pm 1.2 \mathrm{MPa}, \mathrm{p}=0.01$ ). There was no effect of ibuprofen on any measurement tested. Femur results revealed similar patterns.

CONCLUSION-Ibuprofen before exercise did not prevent the skeletal benefits of exercise in female rats. However, exercise that engenders higher bone strains may be required to detect an effect of ibuprofen.

\section{Keywords}

NSAID; mechanical loading; bone strength; ibuprofen; exercise

Address for correspondence: Vanessa D Sherk, PhD, Department of Medicine, Division of Endocrinology, Metabolism \& Diabetes, University of Colorado Anschutz Medical Campus, Aurora, CO 80045, 303-724-3036, Vanessa.sherk@ ucdenver.edu. 


\section{Introduction}

Skeletal tissue adapts to the amount, direction, and speed of mechanical loading forces to prevent fracture during usual activities.(49) Skeletal loading is generated through muscular contractions and ground-reaction forces, making exercise an effective means of improving and maintaining bone health.(1, 24, 27, 50) Adaptation to load requires that the bone sense the load, which occurs primarily by osteocytes. $(5,29)$ Prostaglandin $\mathrm{E}_{2}\left(\mathrm{PGE}_{2}\right)$ is produced from arachidonic acid via cyclooxygenase (COX), and is released by osteoblasts and osteocytes. $(4,25)$ PGE2 increases in response to mechanical stimuli and is necessary for the bone formation response, by mediating gap junction mediated communication in response to loading. $(10,11,36,46)$

Nonsteroidal anti-inflammatory drugs (NSAIDs) are among the most commonly used medications, with a prevalence of $\sim 5-40 \%$ in nonathletic populations, depending on the sample and the NSAID of choice. $(12,20,34,37,39,53)$ Many people take NSAIDs (e.g., ibuprofen) before exercise to prevent pain, and its use is extremely prevalent among athletes. $(2,12,19,47,51,54)$ NSAIDs act by inhibiting (COX) activity, thereby preventing the production of prostaglandins from arachidonic acid. The action of NSAIDs has important wide-spread ramifications for bone health if the result is an inability to appropriately respond to mechanical loading. Rodent studies first demonstrated that the expected increase in bone formation in response to acute mechanical loading is impaired when NSAIDs are administered before, but not after, exercise. $(30,36)$ These findings were later translated into testing the effect of repeated ibuprofen use before or after exercise. Changes in hip BMD were not different in young women taking ibuprofen 1 to 2 hours before exercise sessions during a 9-month exercise training intervention compared to their control group, but taking ibuprofen after exercise resulted in a robust increase in BMD.(28) However, this difference in response was not observed in older adults.(23)

There are limitations to what can be inferred about how NSAID use affects bone quality adaptations to exercise using BMD alone. $(7,31,35)$ Relatively small increases in areal BMD in response to mechanical loading can result in disproportionately large increases in bone strength. $(8,40)$ Important determinants of whole bone strength are bone size and the distribution of bone tissue about its center of mass. Orienting bone tissue further from its center of mass can increase its strength without requiring an increase in bone mass. For a given material property of bone, a 10\% increase in its outer diameter will results in 30$40 \%$ increase in strength, depending on the loading modality.(7) Therefore, if NSAIDs block the increases in cross-sectional bone geometry, then they will also block the increases in bone strength in response to exercise training. There are no previous studies in animals or humans that have determined whether consistently taking NSAIDs prior to repeated exercise bouts prevents bone structural adaptations to mechanical loading. Thus, it is currently unknown whether taking NSAIDs before exercise prevents expected improvements in bone morphometry. It is also unknown whether consistent NSAID use before exercise unfavorably alters resistance to deformation (stiffness), resistance to fracture (strength), and ability to absorb energy (toughness) of bone tissue over long-term exercise training. Therefore, we conducted a randomized, placebo-controlled trial in an animal model to address these gaps in knowledge. 
The purpose of this study was to determine whether NSAID use before exercise prevents increases in bone structure and strength in response to weight-bearing exercise. We hypothesized that consistent administration of ibuprofen before each bout of exercise would prevent the expected increases in bone stiffness and strength in response to long-term exercise training, and that this effect would be explained by blunted improvements in bone cross-sectional geometry.

\section{Methods}

Adult ( 20 wk old) female Wistar rats were placed into groups by stratified randomization by body weight (total $n=43$ ) to Ibuprofen exercise (IBU-EX; $n=10$ ), Ibuprofen sedentary (IBUSED; $n=11$ ), vehicle EX (VEH-EX; n=11), or VEH-SED; n=11.(52) Rats were individually housed in metabolic caging (hanging wire racks) that promotes sedentary behavior when not engaged in programed exercise and kept in a 14:10 light:dark cycle. Rats had access to chow and water ad libitum. Running and drug delivery occurred 5 times per week for 12 weeks. At the end of 12 weeks, body composition (fat mass, bone free lean mass) was measured with quantitative magnetive resonance (qMR; EchoMRI, Houston, TX). Rats were then euthanized by exsanguination under isofluorane anesthesia, blood was collected, and bones were harvested. Bones of the lower limbs were dissected free of soft tissue, wrapped in saline-soaked gauze and stored at $-80 \mathrm{C}$ until further analyses. This study was approved by the University of Colorado Anschutz Medical Campus IACUC (Protocol No. 61414(12)2E).

\section{Drug Delivery}

Ibuprofen (Dose: $30 \mathrm{mg} / \mathrm{kg}$ of body weight; Infants' Ibuprofen Drops (Walgreen Co, Deerfield, IL, $50 \mathrm{mg} / 1.25 \mathrm{~mL}$ ) or vehicle (equivalent volume based on body weight; $1 \%$ methylcellulose and $2 \%$ sucrose in water) was delivered orally with $1 \mathrm{cc}$ needleless syringes 60 min before exercise or at a similar clock time for sedentary controls. Rats were trained to drink fluid from the syringe such that gavage was unnecessary. If a rat did not actively drink all of the ibuprofen solution, then the remainder was slowly ejected into the back of the mouth while being held at a $45^{\circ}$ angle by a technician. This dose and timing was selected based on previous fracture healing studies and pharmacokinetic data of ibuprofen in rats (3, $15,33,42)$. Oral dosing of $20 \mathrm{mg} / \mathrm{kg}$ results in peak plasma concentrations at 45 minutes. (33) The distribution phase (rapid movement from plasma to other tissues) after ip injection is complete within 2 hours, and the half-life is $2-2.5$ hours. The percentage of recovery in urine of ibuprofen and its metabolites after 24 hours is $38 \%$ for a $20 \mathrm{mg} / \mathrm{kg}$ dose and $48 \%$ for a $50 \mathrm{mg} / \mathrm{kg}$ dose.(42) Thus, we timed the exercise bouts to occur while the ibuprofen was at its peak in circulation (including skeletal circulation), and is presumably actively entering into bone cells.

\section{Exercise Intervention}

The exercise prescription was treadmill (Exer-6M Treadmill; Columbus Instruments) running exercise at $20 \mathrm{~m} / \mathrm{min}, 5^{\circ}$ incline, $60 \mathrm{~min} /$ day, for 12 weeks. The exercise dose was ramped up during the first 3 weeks of the intervention. This speed, incline and duration have been effective for inducing increases in bone characteristics such as cortical area, periosteal bone formation rate, BMD, and bone strength. $(9,18,21)$ Exercise bouts ended less than 1 
hour prior to starting the dark cycle $(3 \mathrm{pm})$. This running time-of-day was selected to be consistent with our previous exercise studies.(44) Rats were motivated to complete their daily training by using one or more of the following stimuli: 1) positioning food pellets just out of reach or dangling a novel play item at the head of the treadmill lane; 2 ) shock from an electric grid at the rear of the treadmill (10 volts, $0.5 \mathrm{amps}, 0.75 \mathrm{~Hz}) ; 3)$ application of a bristle brush to the feet on the rear grid; and/or 4) intermittent air puffs to the hindquarters. Rats were scored during each bout of exercise based on the quality of running and amount of encouragement required to complete the exercise bout. Scores of 1-3 indicate that either the rat did not complete the exercise bout, or required constant encouragement to run. Scores of 4-6 indicate that the rat completed the exercise bout, but required multiple reminders to run or intermittent use of encouragement. Scores of 7-10 indicate that the rat completed the exercise bout while remaining on the belt for most-to-all of the bout, requiring little to no encouragement, but the quality of the performance varied from running to the front of the lane and riding to the back of the lane, to continual forward movement. All but two rats were generally compliant to the exercise protocol and required little prompting.

\section{Bone Morphometry}

Microcomputed tomography (Siemens Inveon; Erlangen, Germany) scans were performed on whole femurs and tibiae at a resolution of $30 \mathrm{um}$ and $47 \mathrm{um}$, respectively. A calibration phantom containing known densities of hydroxyapatite $\left(750,250,50,0 \mathrm{mg} / \mathrm{cm}^{3}\right)$ were included in the bone scans to convert greyscales to density values for the finite element models described below. Cortical cross-sectional area (CSA), thickness (CTh), section moduli $\left(\mathrm{Z}_{\min }, \mathrm{Z}_{\max }, \mathrm{Z}_{\mathrm{p}}\right)$ and second moments of area $\left(\mathrm{I}_{\min }, \mathrm{I}_{\max }\right)$ were measured along the diaphyseal shafts of tibiae and femurs using the BoneJ plugin for ImageJ.(14) The volume of interest (VOI) for the tibial shaft was from the tibia-fibula junction to $14.1 \mathrm{~mm}$ proximal, averaged over 150 slices spaced $47 \mu \mathrm{m}$ apart. The VOI for the femoral shaft was $6 \mathrm{~mm}$ in each direction from the femoral midshaft, averaged over 200 slices spaced $30 \mu \mathrm{m}$ apart. Bone slices were realigned about the $\mathrm{z}$-axis using the 'Moments of Inertia' function within BoneJ. Alignment was confirmed through the ImageJ 3D viewer. Slice Geometry was then used to determine cross-sectional characteristics within the VOI.

\section{Mechanical Testing}

Femur strength was quantified with 3-pt bending (loading rate of $0.1 \mathrm{~mm} / \mathrm{sec}$ ) (Insight 30; MTS Systems Corporation; Eden Prairie, MN). The linear portion of the load-deformation curve was confirmed with a linear $\mathrm{r}^{2}>0.99$, and was used to calculate bone stiffness in femora, and the area under the load deformation curve was calculated as the energy to failure. Fracture strength of tibiae was quantified with axial testing, which because of the curvature of the tibia, introduces both compression and bending loads. The ends of each tibiae were potted in blocks of urethane, and force was applied at a strain rate of $0.5 \% / \mathrm{sec}$. Load and displacement data were collected using TestWorks (MTS Systems Corporation, Eden Prairie, MN) software and a 500 N MTS load cell. Stiffness and energy to failure are not reported for tibia, as these measures are affected by the properties of both the bone and the potting material. 


\section{Finite Element Modeling}

MicroCT scans were converted to 3D models with a finite element mesh (Simpleware Ltd.; Exeter, UK) with tetrahedral elements. Femur scans were downsampled to $40 \mu \mathrm{m}$ isometric voxels prior to meshing. The finished models were then imported into Abaqus (Simulia; Providence, RI) for finite element analysis. Each bone element was assigned an elastic modulus based on calibrated greyscale values using the equations described by Keyak et al. (26) In the tibia models, a boundary condition was created to prevent displacement in the distal tibia in all three axes. A compressive load of $200 \mathrm{~N}$ then was applied as ten $20 \mathrm{~N}$ point loads to the proximal tibia. In the femur models, a boundary condition was created to prevent displacement in the proximal femur in all three axes. A compressive load of $250 \mathrm{~N}$ was applied as ten $25 \mathrm{~N}$ point loads to the distal femur. Peak von Mises stress was computed by sampling 50 elements in the region on the periosteum containing the highest stress. An average von Mises stress was computed at the cross-section at the mid-diaphysis in the femur, and just proximal to the junction of the tibia and fibula. Von Mises stresses (distortional mechanical loading) quantify the mechanical behavior of tibiae and femurs under a standardized load. Higher stresses in response to load occur in a bone with a more compliant 3D structure. Further, the region of the highest distortional stress within a bone corresponds to the location where fracture would likely initiate. The FE models of the tibiae were then used to estimate tibial fracture strength under loading similar to that used in the mechanical tests. The BMD of each element was converted to ultimate stress, or local apparent tissue strength, using the relationships of Keyak et al..(26) Using the stress distribution produced by the standard 200-N compressive load, the load was scaled linearly until 3\% of the bone's volume exceeded the local ultimate stress. This load was recorded as the FE-predicted fracture load. There were 9 bones, distributed across the 4 groups, in which the phantom was scanned immediately prior to scanning those bones, rather than being contained within the same scan. Although this effect on failure load prediction was likely small, we did not include these bones in this secondary analysis for the sake of accuracy.

\section{Statistical Analyses}

Data were analyzed with SAS version 9.4. Data are mean \pm SE. To compare the individual (main effects) and combined (interaction) effects of exercise and IBU on morphometry and mechanical testing measurements, two-way ANCOVAs were used, with body weight as the covariate. Main effects (drug and exercise) were explored when interaction effects were not significant. Running performance was compared between the EX groups using a student's ttest. Linear regression was performed and a Bland-Altman plot was created between the FEM-predicted fracture load and the experimental fracture load of tibiae. The level of significance was set at $\mathrm{p}<0.05$ for all tests.

\section{Results}

Running compliance score averaged $7.5 \pm 0.1$ and was similar for the two groups. EX rats gained less weight $(27 \pm 3 \mathrm{~g}$ vs $40 \pm 4 \mathrm{~g}$; $\mathrm{p}<0.05)$ and had a lower final fat mass $(68 \pm 4 \mathrm{~g}$ vs $87 \pm 4 \mathrm{~g} ; \mathrm{p}<0.01)$ than sedentary rats. Final total body mass was not significantly different between EX and SED rats ( $330 \pm 2$ vs $346 \pm 6 \mathrm{~g}$; $\mathrm{p}=0.10$ ). Lean mass was similar among 
exercise groups (EX: $223 \pm 4$ g; SED: $220 \pm 4$ g; $p>0.10$ ). One tibia and one femur sample were lost in imaging data due to motion artifact.

EX significantly improved tibia cortical CSA, Imin, Imax, Zmin, Zmax, and Cth (main effect: all $\mathrm{p}<0.05$; range: 5.2-14.4\% Table 1) and failure load (main effect: $\mathrm{p}<0.02,17.4 \%$; Figure 1a, 1b) after adjusting for body weight. Additionally, EX increased failure load (11.3\%; main effect: $\mathrm{p}<0.01)$ of the femur and femur stiffness (7.5\%; main effect: $\mathrm{p}=0.027$; Figure 1c), but did not change energy to failure ( $p=0.25$, Figure 1d). Generally, the effect of exercise on microCT-based variables was stronger in the tibia than in the femur (see Table, SDC1, Femur uCT results).

Ibuprofen $\times$ exercise interaction effects were not significant for any variables. The effect of exercise on tibia CSA was similar between drug groups, as body weight-adjusted tibia cortical CSA was 9.4\% higher in IBU-EX compared to IBU-SED, and CSA in VEH-EX was $6 \%$ higher than VEH-SED (interaction: $\mathrm{p}=0.48$; post hoc $\mathrm{t}$-tests between EX and SED within drug groups not performed). However, body-weight-adjusted tibia Imax and Imin were $18.3 \%$ and $20 \%$ higher in IBU-EX compared to IBU-SED, and $10.6 \%$ and $7 \%$ higher in VEH-EX compared to VEH-SED (interaction: $\mathrm{p}>0.31$; post hoc t-tests between EX and SED within drug groups not performed).

Bone failure occurs at von Mises stress of approximately $150 \mathrm{MPa}$ (38), which is the red region in Figures 2 and 3. In the tibia, the stress in response to a $200 \mathrm{~N}$ load was lower in EX (main effect: $\mathrm{p}$ \.02), suggesting a more favorable bone structure in exercising rats (Figure 2). Finite element analysis demonstrated that bone failure would initiate on the posterior surface of the tibia toward the outer cortical shell (Figures 2 and 3), and that SED rats would have a larger bone region that would fail in response to the standard load. However, there was no significant effect of ibuprofen (Table 2). For the tibiae included in the development of a failure load criterion ( $n=30)$, FEM-based failure load was not significantly different from the actual failure load $(219.6 \pm 7.0 \mathrm{~N}$ vs. $230.2 \pm 7.1 \mathrm{~N}, \mathrm{p}=0.29)$. The FE-predicted fracture load for the tibia was deemed to have reasonable predictive value for experimentally-measured fracture load, with an $\mathrm{r}^{2}$ value of $0.62(\mathrm{p}<0.001)$ (Figure 4a). All data are provided in the Figure 4a for transparency. However, two obvious outliers (the two tibiae with the highest experimentally-measured fracture loads) were removed for statistical analysis.

\section{Discussion}

This is the first study, to the best of our knowledge, which utilized an exercise program in a preclinical model to determine whether repeatedly taking NSAIDs before exercise attenuates the cortical bone structural and mechanical properties to mechanical loading over long-term exercise training. Our data do not support the hypothesis that taking IBU prior to weight bearing aerobic exercise prevents the skeletal adaptions to exercise training. We found that 12 weeks of treadmill running generated $5-15 \%$ increases in structural parameters (e.g., CSA, Imax) and 7-18\% increases in subsequent mechanical properties (i.e., failure load, stiffness, and energy to failure) compared to sedentary groups. Additionally, through finite 
element modeling, we demonstrated that the mechanical behavior of whole bone improved in exercising rats. However, significant drug effects were not detected.

Skeletal adaptations to exercise training or mechanical loading are site specific, and depend on the interplay between multiple factors such as the number of loads, the magnitude and rate of strain, and frequency of loading bouts.(13, 22, 32) A small number of studies used short-term interventions of externally applied loading on anesthetized rodents. Importantly, that approach has a potential confounding effect of anesthesia, plus externally applied loading removes the role of muscle as an endocrine organ, as well as the loading on bone from muscle contractions. $(17,41)$ Still, injecting NS398 into mice and applying unilateral external loading for 40 loads per day, 3 days per week for 2 weeks during anesthesia did not affect the cortical response to the loading protocol.(45) Previous work that utilized a single bout of loading indicated that the endocortical surfaces of bone appear to be more dependent on PGs for formation than the periosteal surface, which complicates hypotheses about whether NSAIDs are helpful or harmful to skeletal adaptations to loading.(16, 30) If ibuprofen mimicked indomethacin or NS398 on the effect on endocortical versus periosteal bone formation rate and mineral apposition rate, we would expect that the VEH-EX group to have greater endocortical bone formation, resulting in a larger cortical thickness, compared to IBU-EX. This would, in turn, lead to much larger changes in bending resistance and strength in the VEH-EX group. Because ibuprofen is a non-specific COX inhibitor, the observed effect is likely to be more similar to those induced by indomethacin than those induced by NS398, such that a 20-40\% attenuation of the increase in bone size might be hypothesized.

Our results for cross-sectional geometry may provide some clues about possible differences in endosteal and periosteal adaptations that occurred due to exercise. For example, the tibia in VEH-EX rats and IBU-EX rats experienced comparable increases in cortical thickness (6.7\% increase for VEH-EX and 3.4\% increase for IBU-EX) and cortical CSA (6\% increase for VEH-EX and 9.4\% increase for IBU-EX) compared with sedentary rats. Despite the similar changes in cortical thickness and CSA, Imax (a measure of bending resistance) was $18.3 \%$ higher in the IBU-EX group but only $10.6 \%$ higher in the VEH-EX group. Because Imax is proportional to bone width raised to the fourth power, it is possible that the small increase (5.2\%, not significant) in periosteal circumference in the IBU-EX group resulted in the relatively large increase in Imax. Section moduli (Zmax, Zmin, and Zp), which are proportional to bone width raised to the third power, demonstrated similar trends. The variability of our periosteal circumference results was too large to detect significant differences, but future studies could use dynamic histomorphometry to confirm where new bone is added in response to exercise with and without ibuprofen treatment.

The use of FEM provides insight to how the tibiae and femora would be expected to adapt to exercise training.(48) First, distortion in response to a standardized axial compressive load were lowest on the endosteal surface, which should result in smaller structural adaptations at those locations. If the periosteal surface is less dependent on prostaglandins for adaptation to loading,(30) then it would not be surprising that ibuprofen did not prevent the adaptation to exercise. Second, stresses were neither uniform along the diaphysis, nor around its surface. The resulting expectation would be large variability along and around the diaphysis in terms 
of the applied loading stimulus and subsequent adaptation. Thus, the manner in which we measured and reported our structural parameters probably did not capture the 'peak' exercise effect, but we believe it was more representative of the overall exercise effect. In addition, the FE analysis provides additional information as to why the differences in bone strength exist. The combination of 3D geometry, bone mineral density, and applied loading results in a 3D description of stress distribution. The mean finite element analysis (FEA) stress values reported in Table 2 therefore provide a single-number summation of the combined effects of loading and bone structure. Finally, based on agreement with experimental testing, the FEM provides reasonable and highly-significant $(\mathrm{p}<0.001)$ ability to predict tibial fracture load. Therefore, future studies that use CT imaging of the rat hindlimb at multiple time points could implement this analysis method to monitor changes in tibial strength over time.

Contrary to our hypothesis, increases in tibia bone geometry tended to be larger in ibuprofen rats. We acknowledge the possibility that we were not sufficiently powered to detect a significant interaction to permit t-tests for simple effects (i.e., IBU-EX vs IBU-SED and VEH-EX vs VEH-SED). However, our results provide a basis for power analyses for future studies. Because a short-acting, nonselective NSAID was used for this experiment, we do not know whether COX-2 selective NSAIDs, long-acting NSAIDs, or acetaminophen would generate similar results. Sibonga et al. demonstrated that bone formation was attenuated and bone loss was accelerated when ibuprofen was delivered as an implanted pellet, which would have generated a more constant suppression COX, and therefore $\mathrm{PGE}_{2}$.(43) Although studies of the pharmacokinetics of ibuprofen in serum and synovial fluid in rats have been published, much less is known about the kinetics of ibuprofen appearance and clearance in bone tissue.(42) Thus, the amount of ibuprofen in the skeleton during exercise may not have been sufficient to completely inhibit COX in bone. Although NSAID delivery 30 minutes prior to acute loading was enough time to suppress bone formation, and 1 hour should have given ample time for the ibuprofen to reach peak levels within the bone circulation, delivering the ibuprofen 2 hours before exercise may have given more opportunity to inhibit COX within bone cells. $(30,33)$ Because we did not deliver ibuprofen 1 hour before collection of tissues at experiment's end, we cannot verify ibuprofen levels in skeletal tissue at the time exercise was performed. Because of the time course of the bone formation response to mechanical loading in vivo,(6) it is unclear whether taking a single dose of short-acting NSAID around the time when exercise occurs is as relevant when taken in context of repeated bouts of loading. Regardless, this study was designed to mimic the way many people take ibuprofen during free living conditions and further studies will be required to understand whether a more robust suppression of $\mathrm{COX}$ and/or $\mathrm{PGE}_{2}$ is required to block the skeletal adaptations to exercise training. In short, our data do not support the hypothesis that ibuprofen prevents cortical bone structural adaptations to treadmill running when taken before exercise.

\section{Supplementary Material}

Refer to Web version on PubMed Central for supplementary material. 


\section{Acknowledgments}

We wish to acknowledge the following funding sources: NIH P50 HD073063 (PSM), T32 DK007658 (VDS), P30 DK048520, and American College of Sports Medicine Research Endowment (VDS). We have no conflicts of interest to declare. The results of the study are presented clearly, honestly, and without fabrication, falsification, or inappropriate data manipulation. Results of the present study do not constitute endorsement by ACSM.

\section{References}

1. Al Nazer R, Lanovaz J, Kawalilak C, Johnston JD, Kontulainen S. Direct in vivo strain measurements in human bone-a systematic literature review. J Biomech. 2012; 45(1):27-40. [PubMed: 21889149]

2. Alaranta A, Alaranta H, Helenius I. Use of prescription drugs in athletes. Sports Med. 2008; 38(6): 449-63. [PubMed: 18489193]

3. Altman RD, Latta LL, Keer R, Renfree K, Hornicek FJ, Banovac K. Effect of nonsteroidal antiinflammatory drugs on fracture healing: A laboratory study in rats. J Orthop Trauma. 1995; 9(5):392-400. [PubMed: 8537842]

4. Bakker AD, Joldersma M, Klein-Nulend J, Burger EH. Interactive effects of PTH and mechanical stress on nitric oxide and PGE2 production by primary mouse osteoblastic cells. Am J Physiol Endocrinol Metab. 2003; 285(3):E608-13. [PubMed: 12746215]

5. Bonewald LF. The amazing osteocyte. J Bone Miner Res. 2011; 26(2):229-38. [PubMed: 21254230]

6. Boppart MD, Kimmel DB, Yee JA, Cullen DM. Time course of osteoblast appearance after in vivo mechanical loading. Bone. 1998; 23(5):409-15. [PubMed: 9823446]

7. Bouxsein ML. Determinants of skeletal fragility. Best Pract Res Clin Rheumatol. 2005; 19(6):897911. [PubMed: 16301186]

8. Carter DR, Hayes WC. The compressive behavior of bone as a two-phase porous structure. J Bone Joint Surg Am. 1977; 59(7):954-62. [PubMed: 561786]

9. Chen MM, Yeh JK, Aloia JF, Tierney JM, Sprintz S. Effect of treadmill exercise on tibial cortical bone in aged female rats: A histomorphometry and dual energy x-ray absorptiometry study. Bone. 1994; 15(3):313-9. [PubMed: 8068453]

10. Cheng B, Kato Y, Zhao S, et al. PGE(2) is essential for gap junction-mediated intercellular communication between osteocyte-like MLO-Y4 cells in response to mechanical strain. Endocrinology. 2001; 142(8):3464-73.

11. Cherian PP, Cheng B, Gu S, Sprague E, Bonewald LF, Jiang JX. Effects of mechanical strain on the function of gap junctions in osteocytes are mediated through the prostaglandin EP2 receptor. J Biol Chem. 2003; 278(44):43146-56. [PubMed: 12939279]

12. Conaghan PG. A turbulent decade for NSAIDs: Update on current concepts of classification, epidemiology, comparative efficacy, and toxicity. Rheumatol Int. 2012; 32(6):1491-502. [PubMed: 22193214]

13. Cullen DM, Smith RT, Akhter MP. Bone-loading response varies with strain magnitude and cycle number. J Appl Physiol (1985). 2001; 91(5):1971-6. [PubMed: 11641332]

14. Doube M, Klosowski MM, Arganda-Carreras I, et al. BoneJ: Free and extensible bone image analysis in imagej. Bone. 2010; 47(6):1076-9. [PubMed: 20817052]

15. Ferry ST, Dahners LE, Afshari HM, Weinhold PS. The effects of common anti-inflammatory drugs on the healing rat patellar tendon. Am J Sports Med. 2007; 35(8):1326-33. [PubMed: 17452512]

16. Forwood MR. Inducible cyclo-oxygenase (COX-2) mediates the induction of bone formation by mechanical loading in vivo. J Bone Miner Res. 1996; 11(11):1688-93. [PubMed: 8915776]

17. Frost HM. From Wolff's Law to the Utah Paradigm: Insights about bone physiology and its clinical applications. Anat Rec. 2001; 262(4):398-419. [PubMed: 11275971]

18. Fuchs RK, Shea M, Durski SL, Winters-Stone KM, Widrick J, Snow CM. Individual and combined effects of exercise and alendronate on bone mass and strength in ovariectomized rats. Bone. 2007; 41(2):290-6. [PubMed: 17544352]

19. Gorski T, Cadore EL, Pinto SS, et al. Use of nsaids in triathletes: Prevalence, level of awareness and reasons for use. Br J Sports Med. 2011; 45(2):85-90. [PubMed: 19666628] 
20. Hollingshead NA, Vrany EA, Stewart JC, Hirsh AT. Differences in Mexican Americans' prevalence of chronic pain and co-occurring analgesic medication and substance use relative to non-hispanic white and black americans: Results from nhanes 1999-2004. Pain Med. 2016; 17(6): 1001-9. [PubMed: 26814239]

21. Iwamoto J, Takeda T, Sato Y. Effect of treadmill exercise on bone mass in female rats. Exp Anim. 2005; 54(1):1-6. [PubMed: 15725675]

22. Jain NX, Barr-Gillespie AE, Clark BD, et al. Bone loss from high repetitive high force loading is prevented by ibuprofen treatment. J Musculoskelet Neuronal Interact. 2014; 14(1):78-94. [PubMed: 24583543]

23. Jankowski CM, Shea K, Barry DW, et al. Timing of ibuprofen use and musculoskeletal adaptations to exercise training in older adults. Bone Rep. 2015; 1:1-8. [PubMed: 25642444]

24. Judex S, Carlson KJ. Is bone's response to mechanical signals dominated by gravitational loading? Med Sci Sports Exerc. 2009; 41(11):2037-43. [PubMed: 19812513]

25. Kamel MA, Picconi JL, Lara-Castillo N, Johnson ML. Activation of beta-catenin signaling in MLO-Y4 osteocytic cells versus 2T3 osteoblastic cells by fluid flow shear stress and PGE2: Implications for the study of mechanosensation in bone. Bone. 2010; 47(5):872-81. [PubMed: 20713195]

26. Keyak JH, Rossi SA, Jones KA, Skinner HB. Prediction of femoral fracture load using automated finite element modeling. J Biomech. 1998; 31(2):125-33. [PubMed: 9593205]

27. Kohrt WM, Barry DW, Schwartz RS. Muscle forces or gravity: What predominates mechanical loading on bone? MedSciSports Exerc. 2009; 41(11):2050-5.

28. Kohrt WM, Barry DW, Van Pelt RE, Jankowski CM, Wolfe P, Schwartz RS. Timing of ibuprofen use and bone mineral density adaptations to exercise training. JBone MinerRes. 2010; 25(6):141522.

29. Lanyon LE. Osteocytes, strain detection, bone modeling and remodeling. Calcif Tissue Int. 1993; 53(Suppl 1):S102-6. discussion S6-7. [PubMed: 8275362]

30. Li J, Burr DB, Turner CH. Suppression of prostaglandin synthesis with NS-398 has different effects on endocortical and periosteal bone formation induced by mechanical loading. Calcif Tissue Int. 2002; 70(4):320-9. [PubMed: 12004337]

31. Marshall D, Johnell O, Wedel H. Meta-analysis of how well measures of bone mineral density predict occurrence of osteoporotic fractures. BMJ. 1996; 312(7041):1254-9. [PubMed: 8634613]

32. Meakin LB, Price JS, Lanyon LE. The contribution of experimental in vivo models to understanding the mechanisms of adaptation to mechanical loading in bone. Front Endocrinol (Lausanne). 2014; 5(154)

33. Mills RF, Adams SS, Cliffe EE, Dickinson W, Nicholson JS. The metabolism of ibuprofen. Xenobiotica. 1973; 3(9):589-98. [PubMed: 4202799]

34. Morton DJ, Barrett-Connor EL, Schneider DL. Nonsteroidal anti-inflammatory drugs and bone mineral density in older women: The Rancho Bernardo study. J Bone Miner Res. 1998; 13(12): 1924-31. [PubMed: 9844111]

35. Nguyen TV, Center JR, Eisman JA. Femoral neck bone loss predicts fracture risk independent of baseline bmd. J Bone Miner Res. 2005; 20(7):1195-201. [PubMed: 15940372]

36. Pead MJ, Lanyon LE. Indomethacin modulation of load-related stimulation of new bone formation in vivo. Calcif Tissue Int. 1989; 45(1):34-40. [PubMed: 2504461]

37. Qato DM, Alexander GC, Conti RM, Johnson M, Schumm P, Lindau ST. Use of prescription and over-the-counter medications and dietary supplements among older adults in the United States. JAMA. 2008; 300(24):2867-78. [PubMed: 19109115]

38. Reilly DT, Burstein AH. The elastic and ultimate properties of compact bone tissue. J Biomech. 1975; 8(6):393-405. [PubMed: 1206042]

39. Richards JB, Joseph L, Schwartzman K, Kreiger N, Tenenhouse A, Goltzman D. The effect of cyclooxygenase- 2 inhibitors on bone mineral density: Results from the Canadian Multicentre Osteoporosis Study. Osteoporos Int. 2006; 17(9):1410-9. [PubMed: 16791706]

40. Robling AG, Hinant FM, Burr DB, Turner CH. Improved bone structure and strength after longterm mechanical loading is greatest if loading is separated into short bouts. J Bone Miner Res. 2002; 17(8):1545-54. [PubMed: 12162508] 
41. Schnyder S, Handschin C. Skeletal muscle as an endocrine organ: Pgc-1alpha, myokines and exercise. Bone. 2015; 80:115-25. [PubMed: 26453501]

42. Shah A, Jung D. Dose-dependent pharmacokinetics of ibuprofen in the rat. Drug Metab Dispos. 1987; 15(2):151-4. [PubMed: 2882970]

43. Sibonga JD, Bell NH, Turner RT. Evidence that ibuprofen antagonizes selective actions of estrogen and tamoxifen on rat bone. J Bone Miner Res. 1998; 13(5):863-70. [PubMed: 9610751]

44. Steig AJ, Jackman MR, Giles ED, et al. Exercise reduces appetite and traffics excess nutrients away from energetically efficient pathways of lipid deposition during the early stages of weight regain. Am J Physiol Regul Integr Comp Physiol. 2011; 301(3):R656-67. [PubMed: 21715696]

45. Sugiyama T, Meakin LB, Galea GL, Lanyon LE, Price JS. The cyclooxygenase-2 selective inhibitor NS-398 does not influence trabecular or cortical bone gain resulting from repeated mechanical loading in female mice. Osteoporos Int. 2013; 24(1):383-8. [PubMed: 22349912]

46. Thorsen K, Kristoffersson AO, Lerner UH, Lorentzon RP. In situ microdialysis in bone tissue. Stimulation of prostaglandin E2 release by weight-bearing mechanical loading. J Clin Invest. 1996; 98(11):2446-9. [PubMed: 8958205]

47. Thuyne WV, Delbeke FT. Declared use of medication in sports. Clin J Sport Med. 2008; 18(2): 143-7. [PubMed: 18332689]

48. Torcasio A, Zhang X, Duyck J, van Lenthe GH. 3d characterization of bone strains in the rat tibia loading model. Biomech Model Mechanobiol. 2012; 11(3-4):403-10. [PubMed: 21688057]

49. Turner CH. Three rules for bone adaptation to mechanical stimuli. Bone. 1998; 23(5):399-407. [PubMed: 9823445]

50. Turner CH, Robling AG. Designing exercise regimens to increase bone strength. Exerc Sport Sci Rev. 2003; 31(1):45-50. [PubMed: 12562170]

51. Warner DC, Schnepf G, Barrett MS, Dian D, Swigonski NL. Prevalence, attitudes, and behaviors related to the use of nonsteroidal anti-inflammatory drugs (NSAIDs) in student athletes. J Adolesc Health. 2002; 30(3):150-3. [PubMed: 11869920]

52. Webb AA, Gowribai K, Muir GD. Fischer (F-344) rats have different morphology, sensorimotor and locomotor abilities compared to Lewis, Long-Evans, Sprague-Dawley and Wistar rats. Behav Brain Res. 2003; 144(1-2):143-56. [PubMed: 12946605]

53. Wilcox CM, Cryer B, Triadafilopoulos G. Patterns of use and public perception of over-the-counter pain relievers: Focus on nonsteroidal antiinflammatory drugs. J Rheumatol. 2005; 32(11):2218-24. [PubMed: 16265706]

54. Ziltener JL, Leal S, Fournier PE. Non-steroidal anti-inflammatory drugs for athletes: An update. Ann Phys Rehabil Med. 2010; 53(4):278-82. 82-8. [PubMed: 20363203] 

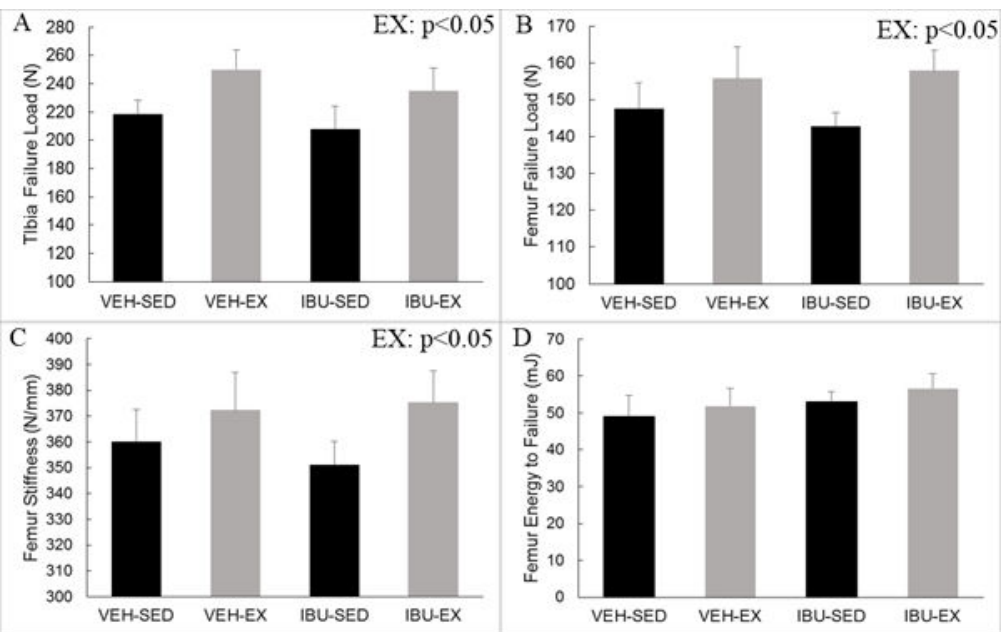

Figure 1.

a-d. 1a. Compressive failure load of the tibiae; 1b. 3 pt bending failure load of femora; 1c. Stiffness of the femoral shaft in response to $3 \mathrm{pt}$ bending; 1d. Energy to failure of femora in response to 3 pt bending. A-C $* \mathrm{p}<0.05 \mathrm{EX}>\mathrm{SED}$. 

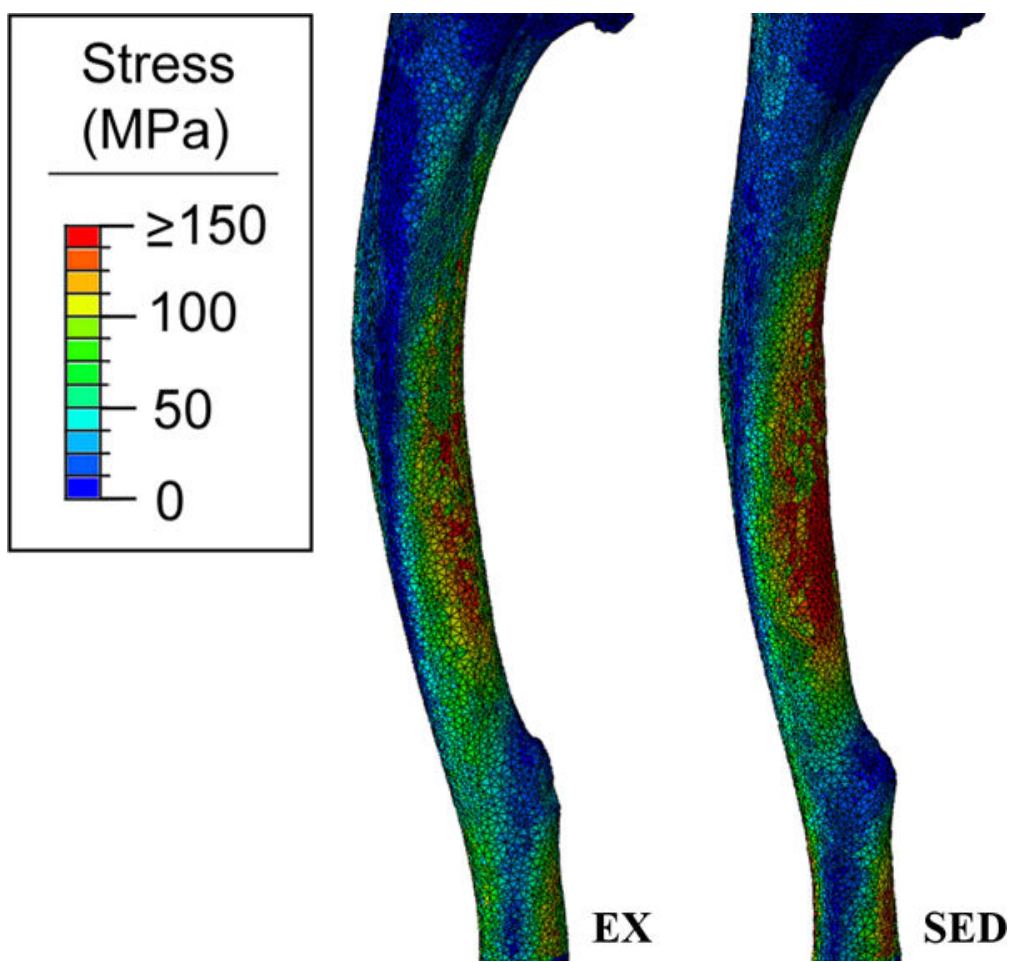

Figure 2.

Representative images of the von Mises stress on the surface of the tibia in response to a standardized compressive load of 200N in EX (left) and SED (right) tibiae. Higher stresses are indicative of a more compliant 3D structure. 


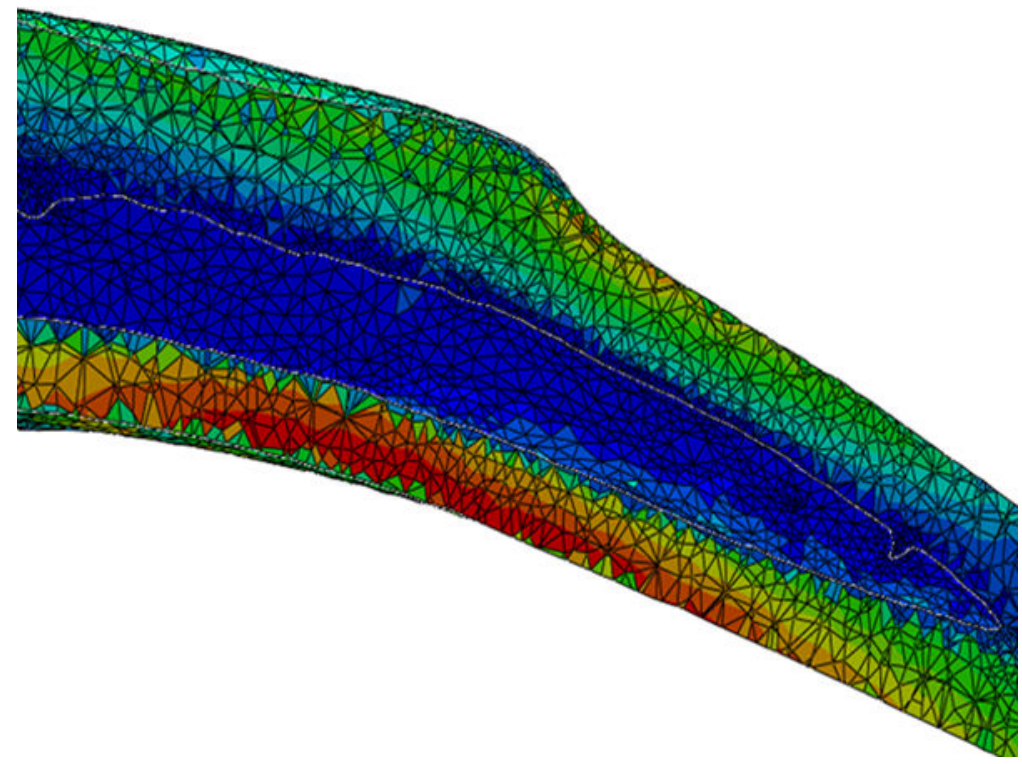

Figure 3.

FEM image of a tibia diaphysis sliced about the sagittal plane. The internal white line is the endocortical border at that slice. The blue seen in the marrow area of the bone is the opposing endocortical surface. Thus, the stresses in response to a standardized compressive load are lowest on the endocortical surface. 

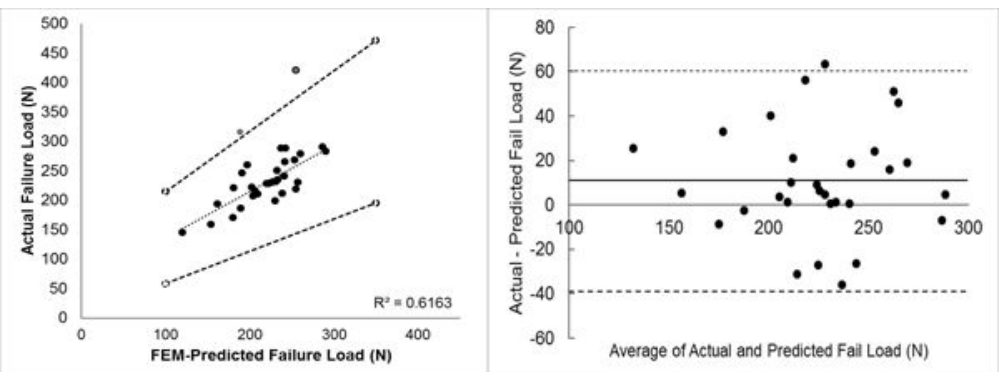

Figure 4.

a and $\mathbf{b}$ Association between FEM-predicted failure load and the failure load from mechanical testing of the tibia. Grey values outside of the $95 \%$ CI were not included in the regression. Bland-Altman Plot of predicted and measured failure loads. 


\section{Table 1}

Cortical structure and image-based estimates of strength of tibiae (Mean $\pm \mathrm{SE})$

\begin{tabular}{|c|c|c|c|c|}
\hline TIBIA & $\begin{array}{c}\text { VEH-SED } \\
(n=11)\end{array}$ & $\underset{(\mathbf{n}=11)}{\text { VEH-EX }}$ & $\begin{array}{c}\text { IBU-SED } \\
(\mathbf{n}=\mathbf{1 0})\end{array}$ & $\underset{(n=10)}{\text { IBU-EX }}$ \\
\hline $\mathrm{CSA}_{\mathrm{ADJ}}\left(\mathrm{mm}^{2}\right)^{a}$ & $5.32 \pm 0.12$ & $5.64 \pm 0.13$ & $5.31 \pm 0.13$ & $5.81 \pm 0.13$ \\
\hline $\mathrm{CSA}_{\mathrm{RAW}}\left(\mathrm{mm}^{2}\right)^{b}$ & $5.40 \pm 0.14$ & $5.55 \pm 0.12$ & $5.34 \pm 0.14$ & $5.80 \pm 0.16$ \\
\hline $\operatorname{Imax} \mathrm{ADJ}\left(\mathrm{mm}^{4}\right)^{a}$ & $4.51 \pm 0.24$ & $4.99 \pm 0.24$ & $4.69 \pm 0.24$ & $5.55 \pm 0.24$ \\
\hline $\operatorname{Imax}{ }_{\mathrm{RAW}}\left(\mathrm{mm}^{4}\right)^{c}$ & $4.65 \pm 0.25$ & $4.82 \pm 0.22$ & $4.75 \pm 0.28$ & $5.53 \pm 0.29$ \\
\hline $\operatorname{Imin}_{\mathrm{ADJ}}\left(\mathrm{mm}^{4}\right)^{b}$ & $2.85 \pm 0.17$ & $3.05 \pm 0.17$ & $2.80 \pm 0.17$ & $3.36 \pm 0.17$ \\
\hline $\operatorname{Imin}_{\mathrm{RAW}}\left(\mathrm{mm}^{4}\right)$ & $2.92 \pm 0.17$ & $2.97 \pm 0.16$ & $2.83 \pm 0.17$ & $3.35 \pm 0.20$ \\
\hline $\operatorname{Zmax}_{\mathrm{ADJ}}\left(\mathrm{mm}^{3}\right)^{a}$ & $2.28 \pm 0.08$ & $2.46 \pm 0.08$ & $2.36 \pm 0.09$ & $2.67 \pm 0.09$ \\
\hline $\operatorname{Zmax}_{\mathrm{RAW}}\left(\mathrm{mm}^{3}\right)^{c}$ & $2.34 \pm 0.09$ & $2.40 \pm 0.08$ & $2.38 \pm 0.11$ & $2.66 \pm 0.10$ \\
\hline $\mathrm{Zmin}_{\mathrm{ADJ}}\left(\mathrm{mm}^{3}\right)^{a}$ & $1.85 \pm 0.07$ & $2.00 \pm 0.07$ & $1.89 \pm 0.07$ & $2.14 \pm 0.07$ \\
\hline $\mathrm{Zmin}_{\mathrm{RAW}}\left(\mathrm{mm}^{3}\right)^{\mathcal{C}}$ & $1.89 \pm 0.07$ & $1.96 \pm 0.07$ & $1.91 \pm 0.09$ & $2.14 \pm 0.09$ \\
\hline $\mathrm{Zp}_{\mathrm{ADJ}}\left(\mathrm{mm}^{3}\right)^{a}$ & $3.66 \pm 0.14$ & $3.91 \pm 0.14$ & $3.72 \pm 0.14$ & $4.22 \pm 0.14$ \\
\hline $\mathrm{Zp}_{\mathrm{RAW}}\left(\mathrm{mm}^{3}\right)^{c}$ & $3.74 \pm 0.14$ & $3.82 \pm 0.14$ & $3.75 \pm 0.16$ & $4.21 \pm 0.17$ \\
\hline Peri ${ }_{\mathrm{ADJ}}(\mathrm{mm})$ & $11.07 \pm 0.20$ & $11.02 \pm 0.20$ & $11.00 \pm 0.21$ & $11.58 \pm 0.21$ \\
\hline Peri $_{\text {RAW }}(\mathrm{mm})$ & $11.12 \pm 0.24$ & $10.96 \pm 0.12$ & $11.02 \pm 0.22$ & $11.57 \pm 0.22$ \\
\hline $\mathrm{Cth}_{\mathrm{ADJ}}(\mathrm{mm})^{a}$ & $0.87 \pm 0.01$ & $0.93 \pm 0.01$ & $0.87 \pm 0.01$ & $0.90 \pm 0.01$ \\
\hline $\mathrm{Cth}_{\mathrm{RAW}}(\mathrm{mm}) b$ & $0.88 \pm 0.02$ & $0.92 \pm 0.01$ & $0.87 \pm 0.02$ & $0.90 \pm 0.01$ \\
\hline \multicolumn{5}{|l|}{$\stackrel{a}{\mathrm{p}} \unlhd 0.01$} \\
\hline \multicolumn{5}{|l|}{$b_{\mathrm{p} \unlhd} \unlhd .05}$, \\
\hline
\end{tabular}

Main effect of exercise; ANCOVA conditioned on body weight. RAW: Unadjusted means; ADJ: Mean adjusted for body weight; CSA: CrossSectional Area; Imax: Maximum $2^{\text {nd }}$ Moment of Area; Imin: Minimum $2^{\text {nd }}$ Moment of Area; Zmax: Maximum Section Modulus; Zmin: Minimum Section Modulus; Zp: Polar Section Modulus; Peri: Periosteal Circumference (mm); Cth: Cortical Thickness; 
Table 2

Mean surface and cross-sectional von Mises stresses (MPa) from finite element modeling. (Mean $\pm \mathrm{SE}$ )

\begin{tabular}{lcccc}
\hline & VEH-SED & VEH-EX & IBU-SED & IBU-EX \\
\hline FEMUR & & & & \\
\hline Von Mises $_{\text {sur }}(\mathrm{MPa})$ & $97.0 \pm 5.3$ & $96.9 \pm 6.7$ & $99.9 \pm 5.7$ & $94.0 \pm 6.0$ \\
Von Mises $_{\text {mid }}(\mathrm{MPa})$ & $37.9 \pm 0.9$ & $37.0 \pm 0.5$ & $38.3 \pm 0.8$ & $37.0 \pm 0.7$ \\
\hline TIBIA & & & & \\
\hline Von Mises $_{\text {sur }^{a}}{ }^{a}(\mathrm{MPa})$ & $201.0 \pm 8.8$ & $173.0 \pm 7.2$ & $201.6 \pm 10.4$ & $172.0 \pm 7.8$ \\
Von Mises $_{\text {junc }}{ }^{a}(\mathrm{MPa})$ & $52.3 \pm 1.6$ & $47.0 \pm 1.5$ & $50.6 \pm 1.7$ & $48.1 \pm 2.2$ \\
\hline
\end{tabular}

${ }_{\mathrm{p}<0.01}^{a}$ Main effect of exercise; Sur: Surface; Mid: Midshaft cross-sectional slice; Junc: Junction = Cross-sectional slice just proximal to where the fibula emerges from the tibia. 